\title{
Dynamic Surface Properties of Mixed Dispersions of Silica Nanoparticles and Lysozyme
}

DOI:

10.1021/acs.jpcb.9b03352

\section{Document Version}

Accepted author manuscript

Link to publication record in Manchester Research Explorer

\section{Citation for published version (APA):}

Milyaeva, O. Y., Campbell, R. A., Gochev, G., Loglio, G., Lin, S. Y., Miller, R., \& Noskov, B. A. (2019). Dynamic Surface Properties of Mixed Dispersions of Silica Nanoparticles and Lysozyme. Journal of Physical Chemistry $B$. https://doi.org/10.1021/acs.jpcb.9b03352

\section{Published in:}

Journal of Physical Chemistry B

\section{Citing this paper}

Please note that where the full-text provided on Manchester Research Explorer is the Author Accepted Manuscript or Proof version this may differ from the final Published version. If citing, it is advised that you check and use the publisher's definitive version.

\section{General rights}

Copyright and moral rights for the publications made accessible in the Research Explorer are retained by the authors and/or other copyright owners and it is a condition of accessing publications that users recognise and abide by the legal requirements associated with these rights.

\section{Takedown policy}

If you believe that this document breaches copyright please refer to the University of Manchester's Takedown Procedures [http://man.ac.uk/04Y6Bo] or contact uml.scholarlycommunications@manchester.ac.uk providing relevant details, so we can investigate your claim.

\section{OPEN ACCESS}




\section{Dynamic surface properties of mixed dispersions of silica nanoparticles and lysozyme}

Olga Yu. Milyaeva ${ }^{a}$, Richard A. Campbell ${ }^{b}$, Georgi Gochev ${ }^{c, d}$, Giuseppe Loglio ${ }^{e}$, Shi-Yow Lin ${ }^{f}$, Reinhard Miller $^{g}$, Boris A. Noskov ${ }^{a} *$

${ }^{a}$ Department of Colloid Chemistry, St. Petersburg State University, Universitetsky pr. 26, 198504 St.

Petersburg, Russia

${ }^{\mathrm{b}}$ Division of Pharmacy and Optometry, University of Manchester, Manchester M13 9PT, UK

${ }^{c}$ Institute of Physical Chemistry, WWU Münster, 48149 Münster, Germany

${ }^{\mathrm{d}}$ Institute of Physical Chemistry, Bulgarian Academy of Sciences, 1113 Sofia, Bulgaria

${ }^{\mathrm{e}}$ Institute of Condensed Matter Chemistry and Energy Technology, CNR-ICMATE, Genova, Italy

${ }^{\mathrm{f}}$ Chemical Engineering Department, National Taiwan University of Science and Technology, Taipei 106,

Taiwan

${ }^{\mathrm{g}}$ Max-Planck-Institute for Colloid and Interface Science, D-14476 Golm, Germany

Corresponding Author

*E-mail: borisanno@ rambler.ru 


\section{Abstract}

The surface properties of mixed aqueous dispersions of lysozyme and silica nanoparticles were studied using surface-sensitive techniques in order to gain insight into the mechanism of simultaneous adsorption of protein/nanoparticle complexes and free protein as well as the resulting layer morphologies. The properties were first monitored in situ during adsorption at the air/water interface using dilatational surface rheology, ellipsometry and Brewster angle microscopy. Two main steps in the evolution of the surface properties were identified. First, the adsorption of complexes did not lead to a significant deviation of the dynamic surface elasticity and dynamic surface pressure from those for a layer of adsorbed lysozyme globules. Second, through gradual displacement of protein globules from the interfacial layer as a result of the further complex adsorption, the layer became more dense with much higher dynamic surface elasticity ( $280 \mathrm{mN} / \mathrm{m}$ compared with $\sim 80 \mathrm{mN} / \mathrm{m}$ for a pure protein layer). These layers were shown to be fragile and could be easily broken into separate islands of irregular shape by a weak mechanical disturbance. The layer properties were then monitored following their transfer to solid substrates using atomic force microscopy and scanning electron microscopy. These layers were shown to consist of nanoparticles surrounded by a rough shell of protein globules while some particles tended to form filamentous aggregates. This comprehensive study provides new mechanistic and morphological insight into the surface properties of a model protein/nanoparticle system, which is of fundamental interest in colloidal science and can be extended to systems of physiological relevance. 


\section{Introduction}

Interactions between nanoparticles and biomacromolecules have recently attracted attention of numerous researchers because of various biological and medical applications ${ }^{1,2}$. The small size of the complexes formed between nanoparticles and biomacromolecules allows them to participate in cell biochemical processes and to penetrate into hard-to-reach areas, for example, to the brain ${ }^{3-5}$. When the nanoparticles enter a living organism, they immediately interact with biological fluids and become coated by various biomolecules (proteins, enzymes, polysaccharides, etc. $)^{1,4,6,7}$.

Adsorption of biomolecules on the surface of nanoparticles gives them new properties and affects their further functioning inside the body and their interactions with cells ${ }^{3,8,9}$. The corona of biomolecules on the surface of solid nano- and microparticles may differ significantly from adsorption films of these substances on a flat surface and have a distinct composition and structure of adsorbed proteins ${ }^{10}$. In spite of the fact that human biological fluids contain thousands of proteins, the corona consists mainly of 10-50 different proteins, which have the greatest affinity to the surface of the particles ${ }^{11}$. The structure of the protein globule can vary significantly under interactions with nanoparticles ${ }^{5,12-14}$. The conformational transitions, structural defects, partial denaturation, arising in the course of adsorption on a curved surface of a particle, lead to the distortion of signals from some groups by which cells recognize foreign objects $^{3,5,15}$. On the one hand, this may result in disruption of the cell functioning. On the other hand, it can allow complexes to overcome protective barriers of the body in the delivery of medicine to the target.

Complexes of lysozyme (a well-studied model protein) and silica nanoparticles (model hydrophilic nanoparticles) are an example of systems where the globular structure of a protein can vary significantly. The change of protein structure has been studied by methods of differential scanning calorimetry ${ }^{16}$, fluorescence spectroscopy ${ }^{17}$ and circular dichroism ${ }^{17-19}$. It was shown that during adsorption on nanoparticles both the tertiary and secondary structures of lysozyme can change, the content of alpha- 
helices can decrease and the number of random coils increases. Usually the characteristic time of lysozyme adsorption is much less than the time of structural changes ${ }^{17}$.

Estimations of the surface concentration and the number of lysozyme molecules per silica nanoparticle $^{12}$ indicate that the maximum coverage in a monolayer is already reached at $\mathrm{pH} 7$. Kumar et al. showed that at neutral $\mathrm{pH}$, the limiting values of the surface coverage are 90 and 270 lysozyme molecules per nanoparticle of sizes a diameter 16 and $25 \mathrm{~nm}$, respectively ${ }^{20}$. Interactions of silica nanoparticles with lysozyme are dominated by electrostatic forces, so parameters such as the $\mathrm{pH}$ and ionic strength of the solution affect the stoichiometry of the complex and the state of the protein inside the corona $^{12}$. The protein adsorption increases at the approach of the isoelectric point. This can be explained by the formation of a secondary adsorption layer. However, even in this situation a more preferable sideon orientation of the adsorbed molecules is probably preserved ${ }^{13,21,22}$.

Interactions of positively charged groups of the protein with the surface of negatively charged nanoparticles result in a maximum perturbation of the globular structure in the areas of direct contact ${ }^{13,23}$. Increase of the particle size and decrease of surface curvature leads to changes of the lysozyme conformation due to an increase of electrostatic interactions at low values of the solution ionic strength $^{22,24}$. UV-visible spectroscopy, dynamic light scattering and small-angle neutron scattering showed that the adsorption of lysozyme increases exponentially with protein concentration and depends on the available surface area ${ }^{25,26}$. An increase in the protein concentration can result in an aggregation of complexes and to the development of their fractal structure ${ }^{26,27}$.

In spite of intensive research on protein/nanoparticle systems during the last decade, many aspects of their interactions remain unclear. Indeed the results of various characterization methods do not always agree among themselves. For example, recent studies have not managed to confirm earlier conclusions on the unfolding of lysozyme globules upon adsorption on the surface of silica nanoparticles ${ }^{28}$. Further, the influence of an inhomogeneous charge distribution on the surface of protein globules and the dense part of the electric double layer ions has not yet been investigated ${ }^{25}$. The encountered difficulties may be 
connected with a relatively small number of experimental methods suitable for the investigation of the protein corona of nanoparticles present in a bulk solution. At the same time, it has been shown recently that the complexes between proteins and nanoparticles are characterized by noticeable surface activity, and therefore, characterization of their adsorption at interfaces using surface-sensitive techniques can give additional information on their interactions ${ }^{29,30}$. In particular it was shown that the adsorption layers of the complexes of silica nanoparticles with fatted and defatted human serum albumin have different properties due to different protein conformations ${ }^{29}$. To the best of our knowledge the mixed adsorption layers of silica nanoparticles with lysozyme have not been studied yet.

Among the characterization methods available for films formed at the air/water interface, the methods of dilatational surface rheology are especially sensitive to the conformations of macromolecules in the adsorption layer and the layer mesoscopic structure ${ }^{31-34}$. Further, techniques such as ellipsometry and Brewster angle microscopy can provide information on the interactions as well as the lateral morphology of the interface, respectively. Additional imaging techniques such as scanning electron microscopy and atomic force microscopy have the potential to provide deeper insight into the protein/nanoparticle interaction following transfer of films formed at the air/water interface to solid substrates. However, to the knowledge of the authors, such a depth of insight in such a system has not been provided by the application of all of these techniques to a single system of relevance to nanotoxicology to date.

In this work, all five of the techniques discussed above are applied the adsorption layers of complexes between lysozyme and silica nanoparticles at the air/water interface at $\mathrm{pH} 7$. In this case, the components are oppositely charged and the formation of stable complexes is expected due to strong electrostatic interactions. The main aim of the work is the elucidation of the formation mechanism of the adsorption layer of protein/nanoparticle complexes at the air/water interface using mixed dispersions of silica nanoparticles and lysozyme as a model system. The lateral pressure in the adsorption layer (surface pressure) can exceed strongly the disjoining pressure between the particles in dilute bulk dispersion. 
Therefore other aims are the investigation of the interactions between protein coronas in the surface layer and the examination of recent results on the corona structure by the methods of interface science. The obtained data indicate that the developed experimental approach can be also useful for more complex protein/nanoparticle systems.

\section{Experimental Section}

The dynamic dilatational surface elasticity was measured by the oscillating ring method, which has been described in detail elsewhere ${ }^{35,36}$. A glass ring with the main axis perpendicular to the investigated liquid surface was partly immersed into the liquid. The inner surface of the ring was sandblasted to improve wetting. The ring oscillations along its axis led to oscillations of the liquid surface area as a result of periodical changes of the meniscus shape at the inner ring surface. The frequency and amplitude of the surface area oscillations were $0.1 \mathrm{~Hz}$ and $7 \%$ respectively. The corresponding oscillations of the surface tension $\gamma$ were measured by the Wilhelmy plate method. The complex dynamic surface elasticity $\mathrm{E}$ was determined from the oscillations of the surface tension $\gamma$ and surface area $A$ according to the following relation:

$E(\omega)=E_{r e}+i E_{i m}=\frac{\delta \gamma}{\delta \ln A}$

where $\mathrm{E}$ and the increments of surface tension $\delta \gamma$ and surface area $\delta \mathrm{A}$ are complex quantities.

In the case of a purely elastic system, $\mathrm{E}$ becomes a real quantity and coincides with $\mathrm{E}_{\mathrm{re}}$ (storage modulus). In a more general case, $\mathrm{E}$ depends not only on the amplitudes of surface tension and surface area oscillations but also on the phase shift between these two quantities and becomes a complex quantity where the imaginary part $\mathrm{E}_{\mathrm{im}}$ (loss modulus) describes the viscous contribution. The imaginary part of the complex dynamic surface elasticity of the solutions under investigation proved to be much less than the real part. Therefore, only the results for the storage modulus of the dynamic surface elasticity are discussed below. 
The null-ellipsometer Multiskop (Optrel GBR, Germany) at a single wavelength of $632.8 \mathrm{~nm}$ was applied to estimate the adsorbed amount using a fixed compensator $\left( \pm 45^{\circ}\right)$ and a 2 -zone averaging nulling scheme. All the ellipsometric measurements were performed at an incidence angle of $49^{\circ}$ close to the Brewster angle because this condition ensured the highest sensitivity of the ellipsometric angles to the properties of the adsorption layer. The difference $\Delta_{\text {surf }}$ between the ellipsometric angles for the investigated solutions $\Delta_{\mathrm{S}}$ and pure water $\Delta_{0}$ is approximately proportional to the adsorbed amount $\Gamma$ in a model of a thin uniform isotropic layer of a single component, which is separated by sharp interfaces from the two ambient media ${ }^{37}$.

$$
\Delta_{\text {suf }}=\Delta_{s}-\Delta_{0}=k_{\text {suf }} \Gamma
$$

where

$$
k_{\text {surf }}=\frac{g(\theta)\left(\varepsilon_{\text {surf }}-\varepsilon_{1}\right)\left(\varepsilon_{\text {surf }}-\varepsilon_{2}\right)}{\varepsilon_{\text {surf }} \lambda \rho}
$$

and where $g(\theta)$ is a coefficient that depends only on the angle of incidence and the properties of the bulk phase, $\lambda$ is the wavelength, $\rho$ is the density of the adsorption layer, $\varepsilon_{\text {surf }}, \varepsilon_{1}$ and $\varepsilon_{2}$ are the dielectric constants of the layer and the two ambient media (air and aqueous solution, respectively). The experimental error of the ellipsometric angle $\Delta_{\text {surf }}$ is about $\pm 0.1^{\circ}$. At the same time, the distinctions between different kinetic dependencies for the same solution may exceed this value due to possible fortuitous mechanical disturbances in the course of long lasting measurements.

The morphology of adsorption films of the protein/nanoparticle complexes was determined by Brewster angle microscopy (BAM) (BAM 1, Nanofilm Technology, Germany), scanning electron microscopy (SEM) (Zeiss Gemini LEO 1550, Germany), and atomic force microscopy (AFM) (NTEGRA Prima setup, NT-MDT, Russia). For AFM measurements, the adsorption films were transferred from the liquid surface onto a mica substrate by the Langmuir-Blodgett method. Each sample for AFM was dried in a desiccator at room temperature for two days. All the measurements were carried out in semi contact mode. For SEM measurements the adsorption films were transferred from the liquid surface onto a glass substrate by the Langmuir-Schaefer method. Each sample for SEM was placed onto a sample holder, 
dried at room temperature, and subjected to sputtering with a gold/palladium mixture to avoid electron charging during SEM analysis. The samples were studied at an operating voltage of $3 \mathrm{kV}$ and different magnifications.

The size and $\zeta$-potential of the protein/nanoparticle complexes in the bulk solution were measured by Zetasizer ZS Nanoanalyzer (Malvern, UK). The measurements were carried out at a scattering angle of $173^{\circ}$

The aqueous dispersions of silica nanoparticles were prepared by diluting the commercial reagent LUDOX (Sigma Aldrich, Germany) with a particle concentration of $30 \mathrm{wt} \%$. The dynamic light scattering showed that LUDOX nanoparticles were almost monodisperse (index of polydispersity was about 0.134) with the average diameter of about $20 \mathrm{~nm}$. Lysozyme (Sigma Aldrich, Germany) with a molecular weight of 14,300 was used without further purification.

Lysozyme solutions were prepared by diluting the stock solution with a concentration of $1.256 \mathrm{~g} / \mathrm{l}$. All the solutions were stored in a refrigerator at temperatures below $10^{\circ} \mathrm{C}$ no longer than two days. The nanoparticle dispersions were treated in an ultrasonic bath for 15 minutes prior to use in order to avoid possible aggregation. The dispersions of the complexes were prepared by mixing equal volumes of the protein solution of a given concentration and a dilute dispersion of nanoparticles. The lysozyme solution was added drop by drop to the dispersion of silica nanoparticles under continuous stirring. The concentration of lysozyme was changed but the concentration of nanoparticles was always 0.2 wt. $\%$.

All the solutions at $\mathrm{pH} 7$ were prepared in phosphate buffer (Sigma Aldrich) with the ionic strength of 0.02 M. Triply distilled water was used for these purposes. An apparatus made from glass was used during the last two steps of distillation. The surface tension of the buffer solutions without protein was $72.8 \mathrm{mN} / \mathrm{m}$. All the measurements were performed at a temperature of $20 \pm 1^{\circ} \mathrm{C}$. 


\section{Results}

Fig. 1 shows the results of dynamic light scattering of lysozyme/silica nanoparticle dispersions. The diameter of the complexes and their $\zeta$ - potential are constant in the error limits and close to the data for dispersions of silica nanoparticles without protein in the range of lysozyme concentrations from $2.5 \times 10^{-7}$ to $2 \times 10^{-6} \mathrm{M}$. Silica nanoparticles used in this work has an average diameter of about $20 \mathrm{~nm}$. Lysozyme is a small compact globular protein with the dimensions $45 \times 30 \times 30 \AA^{38}$. Therefore, one can neglect any aggregation in the bulk phase in this concentration range. Further increase of protein concentration leads to a noticeable increase of the particle size indicating the beginning of aggregation. At concentrations approaching $1 \times 10^{-5} \mathrm{M}$ the aggregate size increases abruptly and it is possible to observe the sedimentation of macroscopic aggregates in agreement with recent studies where a bimodal size distribution of the complexes was discovered ${ }^{24,39}$. One of the peaks of the size distribution was associated with the beginning of the formation of a new phase. The lysozyme concentration corresponding to the phase separation depends strongly on the solution $\mathrm{pH}$ and ionic strength ${ }^{40,41}$. The nuclei of the new phase have a fractal structure with a high degree of branching. At relatively low protein concentrations, the fractal aggregates coexist with non-aggregated lysozyme/nanoparticle complexes, and at high concentrations with free protein molecules ${ }^{20,41,42}$. 


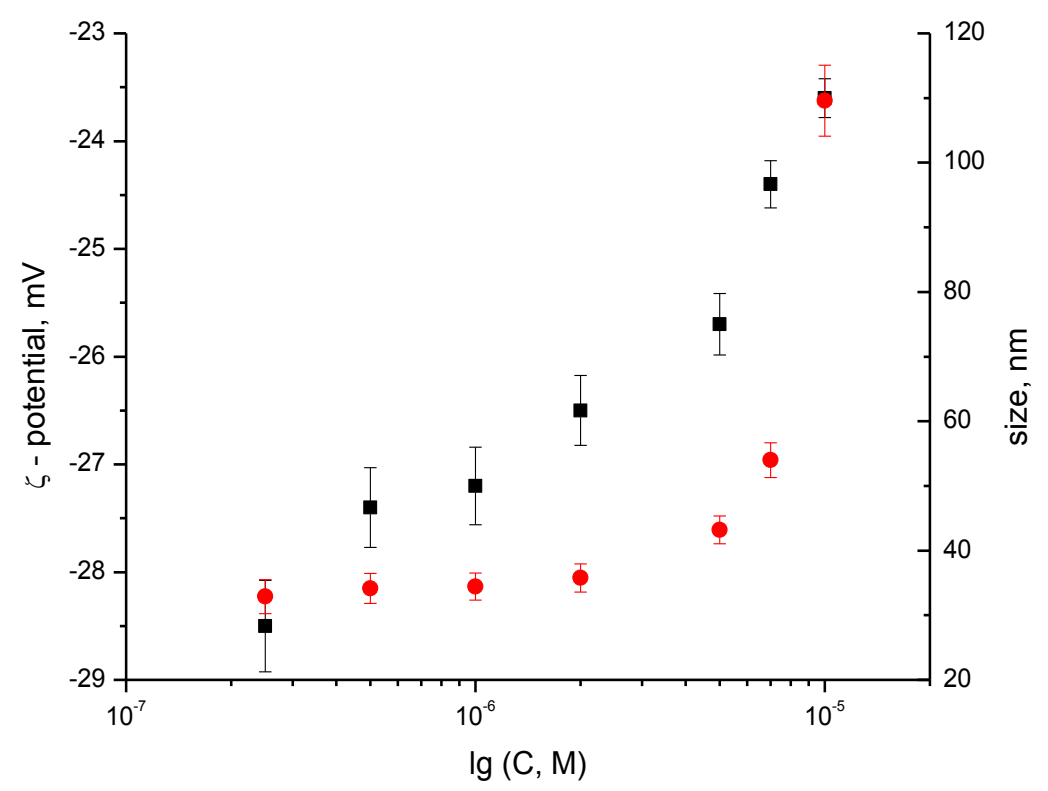

Fig. 1. Concentration dependencies of $\zeta$-potential (black squares) and size (red circles) of lysozyme/silica nanoparticle complexes.

The dynamic surface elasticity (Fig. 2) and the dynamic surface pressure (Fig. 3) of aqueous dispersions were measured as a function of surface age and protein concentration at constant $\mathrm{pH}$ and ionic strength of the solution. The error limits of the dynamic surface elasticity and dynamic surface pressure are in the range \pm 2 to $\pm 4 \mathrm{mN} / \mathrm{m}$, and we do not show error bars in the figures because of their small size. Note that the experimental points in Fig. 3 represent only the averaged data over a few periods of ring oscillations. At lysozyme concentrations beyond $3 \times 10^{-6} \mathrm{M}$ the system can be characterized by a nonlinear response to surface area oscillations. The surface tension can approach the value for water in the course of surface expansion even at small amplitudes of the surface area oscillations (7\%). After that the values remain approximately constant for some time until the surface compression is started and the surface tension decreases again (supporting information, Figs. $1 \mathrm{~S}$ and $2 \mathrm{~S}$ ). As a result, the amplitude of the surface area oscillations influences the measured kinetic dependencies of the dynamic surface 
properties. In particular, the increase of the dynamic surface elasticity after the region of slow changes becomes more abrupt if the amplitude decreases.

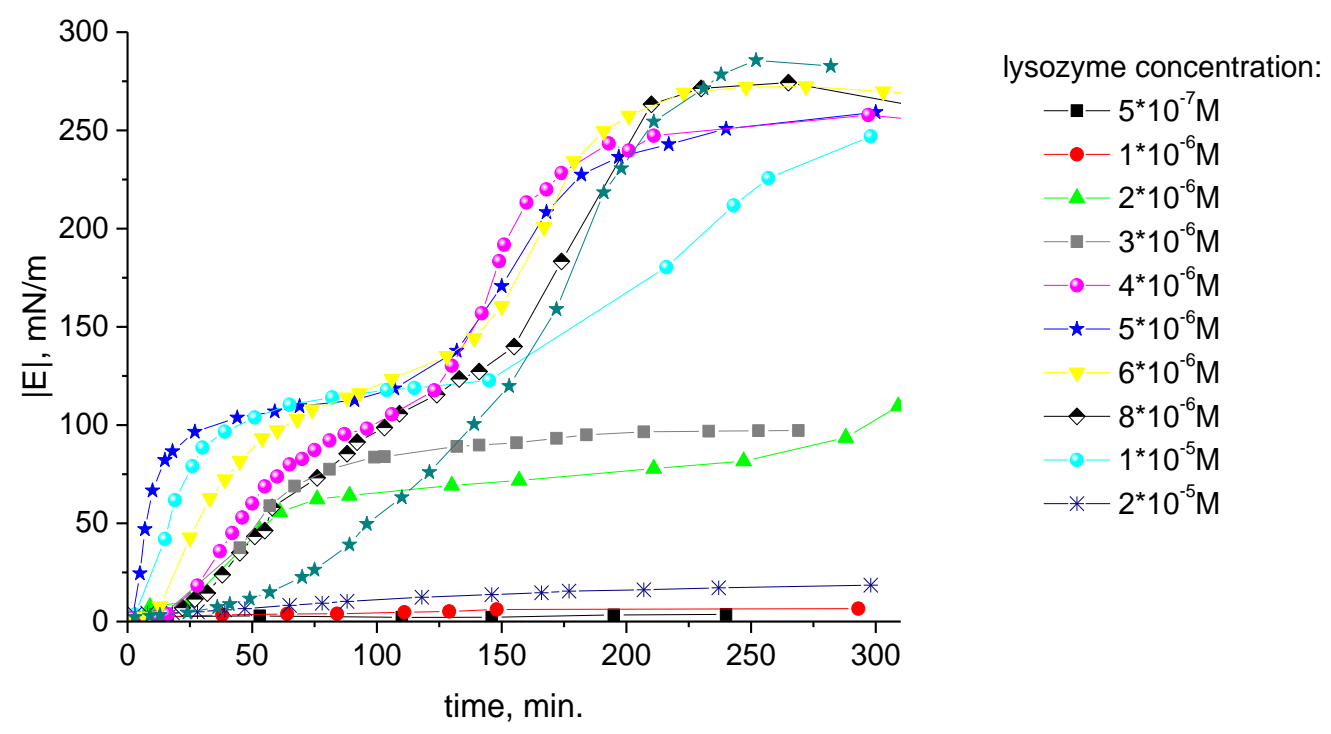

Fig. 2. Kinetic dependencies of the dynamic surface elasticity of mixed dispersions of silica nanoparticles $(0.2 \mathrm{wt} . \%)$ and lysozyme at $\mathrm{pH} 7$ and various protein concentrations.

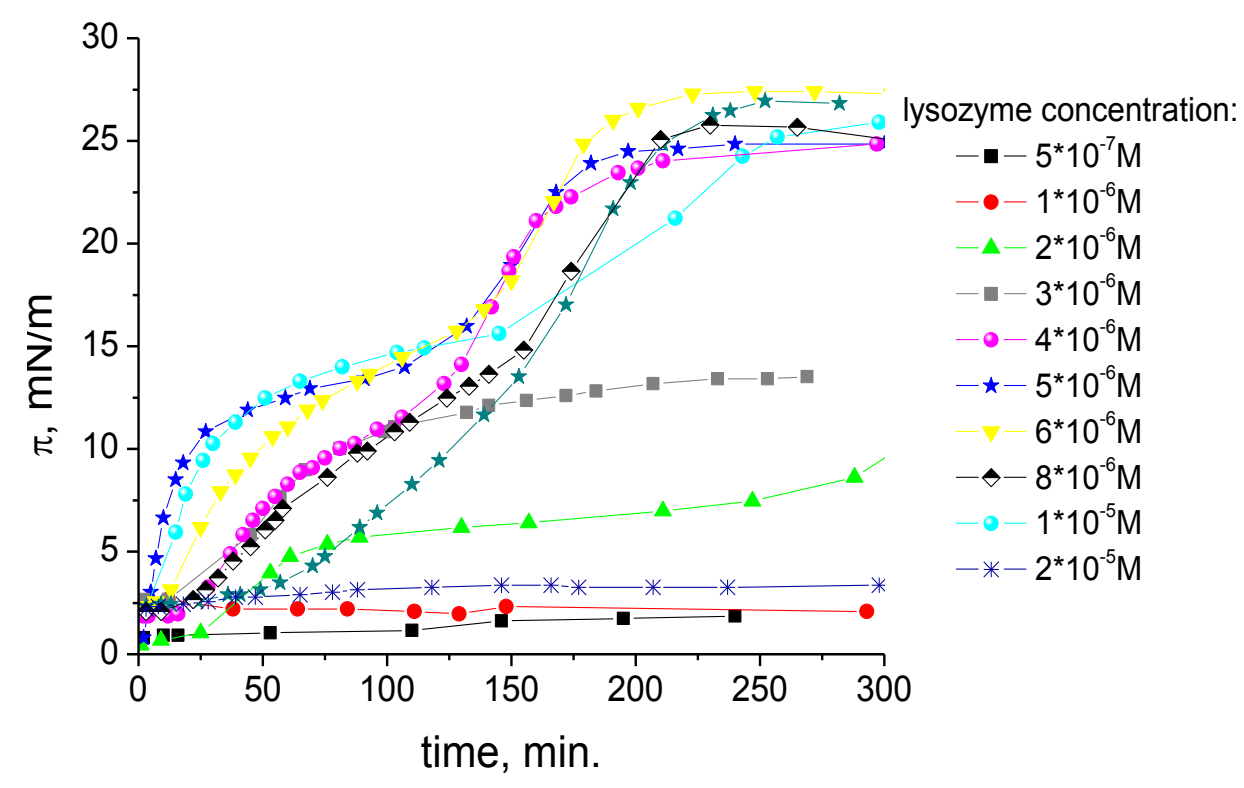

Fig. 3. Kinetic dependencies of the surface pressure of mixed dispersions of silica nanoparticles $(0.2$ wt.\%) and lysozyme at $\mathrm{pH} 7$ at various protein concentrations. 
The kinetic dependences of the dynamic surface properties can be divided into four groups corresponding to low $\left(\mathrm{C}_{\text {protein }}<2 \times 10^{-6} \mathrm{M}\right)$, intermediate $\left(2 \times 10^{-6} \leq \mathrm{C}_{\text {protein }}<4 \times 10^{-6} \mathrm{M}\right)$, high $\left(4 \times 10^{-6}\right.$ $\left.\leq \mathrm{C}_{\text {protein }}<1 \times 10^{-5} \mathrm{M}\right)$ and very high $\left(\mathrm{C}_{\text {protein }} \geq 1 \times 10^{-5} \mathrm{M}\right)$ protein concentrations. At low lysozyme concentrations, all changes of the dynamic surface properties are close to the error limits. The adsorption of pure lysozyme at the same low concentrations also does not lead to noticeable changes of the dynamic surface properties (supporting information, Fig. 3S). In the region of intermediate protein concentrations, the dynamic surface elasticity and dynamic surface pressure increase, reaching finally the values close to the results for pure lysozyme solutions (supporting information, Fig. 3S). This similarity suggests that the protein-protein interactions between adsorbed macromolecules, the macromolecules and coronas of nanoparticles, and between coronas themselves determine the dynamic surface properties of the dispersions. The influence of the cores of the complexes is probably insignificant in this concentration range.

At high protein concentrations, one can observe a transition from the dynamic surface properties, which are characteristic for globular proteins, to significantly higher values (Fig. 2). The similar high values of the dynamic surface elasticity have been obtained previously for dispersions of solid amphiphilic nanoparticles ${ }^{43}$. The surface pressure also reaches the values exceeding the results for pure lysozyme solutions (Fig. 3). The dynamic surface elasticity can be more than 2 times higher than the corresponding data for lysozyme solutions without nanoparticles. One can assume that the high surface elasticity is a consequence of the penetration of nanoparticles into the surface layer and of the influence of solid cores of the complexes on the interactions between them. On the other hand, the high surface pressure $(>20 \mathrm{mN} / \mathrm{m})$ indicates a higher local concentration of hydrophobic amino acid residues in the proximal region of the surface layer than in the adsorption layer of pure lysozyme, probably due to a dense packing of protein/nanoparticle complexes in this region. The shape of the kinetic curves in Figs. 2 and 3 suggests that there are significant changes in the structure of the adsorption layer. At the first step, the structure is similar to that of the adsorption layer of pure protein solutions but changes in the course of 
formation of a dense layer of protein/nanoparticle complexes at the approach to steady state. The surface activity of proteins has been shown to increase with diminishing of the protein net charge ${ }^{44}$. In this context, the detected decrease of zeta potential in Fig. 1 suggests enhancement of the surface activity of protein/nanoparticle complexes in comparison to individual protein globules.

At very high protein concentrations, the system loses its stability. The size of aggregates in the bulk phase increases dramatically and one can observe a gradual sedimentation of macroscopic aggregates. The concentration of hydrophobic groups in the surface layer decreases and the dynamic surface properties approach the values for water.

If the measured dynamic surface elasticity is plotted as a function of surface pressure, all the experimental data are close to a straight line (Fig. 4). At low surface pressures $(<15 \mathrm{mN} / \mathrm{m})$, the dependence of $|\mathrm{E}|$ on $\pi$ almost coincides with the results for pure lysozyme solutions (supporting information, Fig. 4S). and thereby has no indications of the destruction of the protein's tertiary structure ${ }^{34}$. Moreover, preservation of the slope of $|\mathrm{E}|(\pi)$ dependences in the entire range of surface pressures indicates that the interactions between protein globules, free or bounded to nanoparticles, in the surface layer gives the main contribution to the surface pressure. 


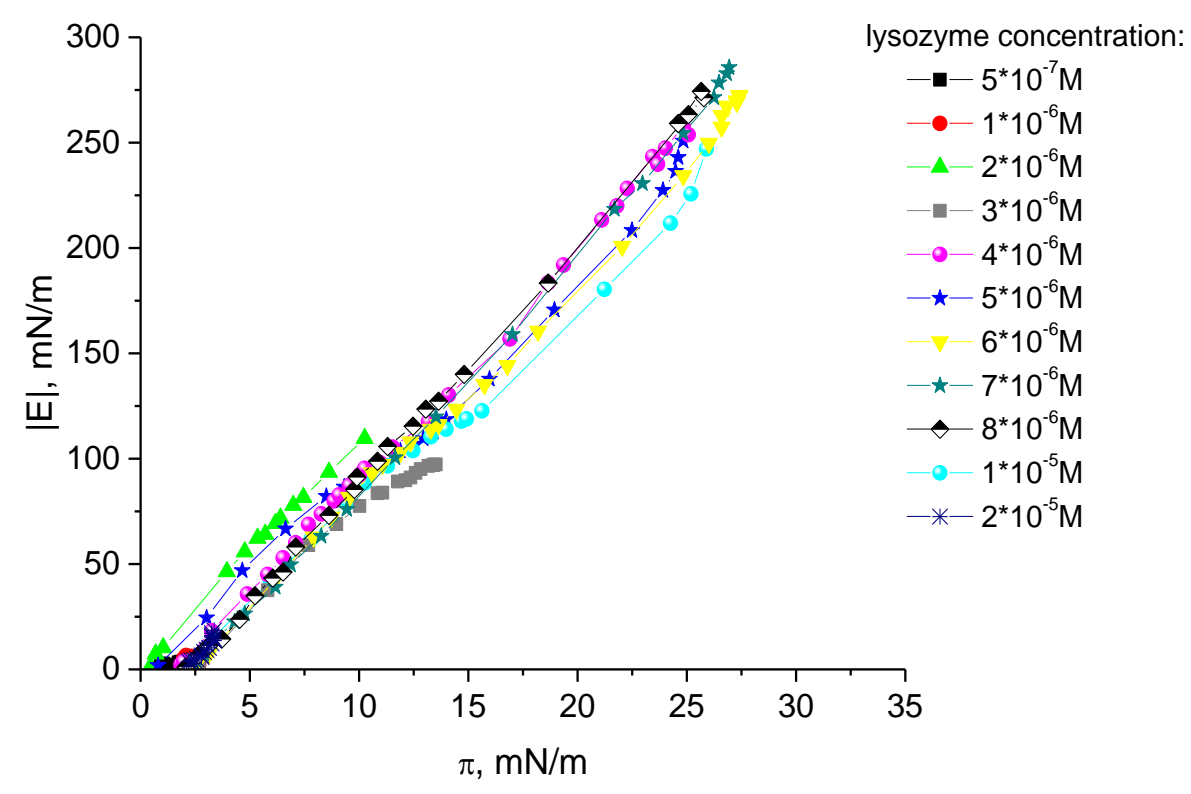

Fig. 4. Dependencies of the dynamic surface elasticity on surface pressure for mixed dispersions of silica nanoparticles $(0.2 \mathrm{wt} . \%)$ and lysozyme at $\mathrm{pH} 7$ and at various protein concentrations.

Therefore, it is possible to assume that lysozyme preserves its globular structure at the surface of the nanoparticles and in the course of the adsorption of complexes at the air/water interface. The conclusion on the preservation of the protein's tertiary structure in its complexes with silica nanoparticles is supported by recent studies of lysozyme/nanoparticle interactions in the bulk phase ${ }^{28}$. On the other hand, the obtained results indicate that the lysozyme's tertiary structure is preserved to a great extent even in the case of a dense packing of the complexes in the adsorption layer, when the surface pressure reaches $\sim 27 \mathrm{mN} / \mathrm{m}$. The elastic force due to the deformation of protein shells of nanoparticles in the course of compression of the adsorption layer increases proportionally to the surface pressure (Fig. 4).

Measurements of the ellipsometric angle $\Delta_{\text {surf }}$ indicate a high concentration of nanoparticles in the surface layer already at protein concentrations higher than $3 \times 10^{-6} \mathrm{M}$ (Fig. 5). In this case, the angle close to steady state is more than two times larger than the corresponding values for solutions of pure lysozyme. Although the diameter of silica nanoparticles exceeds the size of lysozyme globules by almost an order of magnitude, the strong increase of $\Delta_{\text {surf }}$ can be connected not only with an increase of the 
thickness of the adsorption layer as a result of the adsorption of nanoparticles but also with the difference in refractive indices of $\mathrm{SiO}_{2}$ and lysozyme $\left(\mathrm{n}_{\mathrm{SiO} 2}=1.475^{45}\right.$ and $\left.\mathrm{n}_{\text {protein }}=1.38^{46}\right)$.

The rate of adsorption increases significantly with the increase of lysozyme concentration. At concentrations beyond $3 \times 10^{-6} \mathrm{M}, \Delta_{\text {surf }}$ reaches steady state values in less than 8 hours and almost does not change with concentration up to about $8 \times 10^{-6} \mathrm{M}$. The comparison with Fig. 2 shows that the main increase of the surface elasticity is accompanied by only a relatively small increase of the surface concentration. The initial step of adsorption is characterized by noticeable temporal fluctuations of the ellipsometric angle (Fig. 5). These fluctuations exceed the error limits and indicate the heterogeneity of the adsorption layer on a scale of tens or hundreds of micrometers and the mobility of patches of surface aggregates in the layer as they move in and out of the probed area of the laser beam. Such fluctuations have been noted previously at low concentrations of adsorbed layers of human serum albumin ${ }^{47}$. If $\Delta_{\text {surf }}$ reaches about $70 \%$ of its steady state value, the fluctuations disappear. In this case, it is likely that the layer becomes more homogeneous and/or immobile and the temporal fluctuations of the signal strongly decrease. At high protein concentrations $\left(\geq 1 \times 10^{-5} \mathrm{M}\right)$, the ellipsometric angle decreases abruptly. A possible explanation consists of an abrupt increase of the adsorption layer thickness, thereby in violation of the main conditions of the validity of relations (1)-(2), but the concomitant strong decrease of the dynamic surface elasticity (Fig. 2) and the appearance of large macroscopic aggregates in the bulk phase indicate another cause of the observed effect. It is more likely that the growth of aggregates in the bulk phase is accompanied by the transfer of lysozyme/nanoparticle complexes from the interface into the bulk and thereby by the destruction of the network of complexes at the interface and by a strong decrease of the surface concentration. 


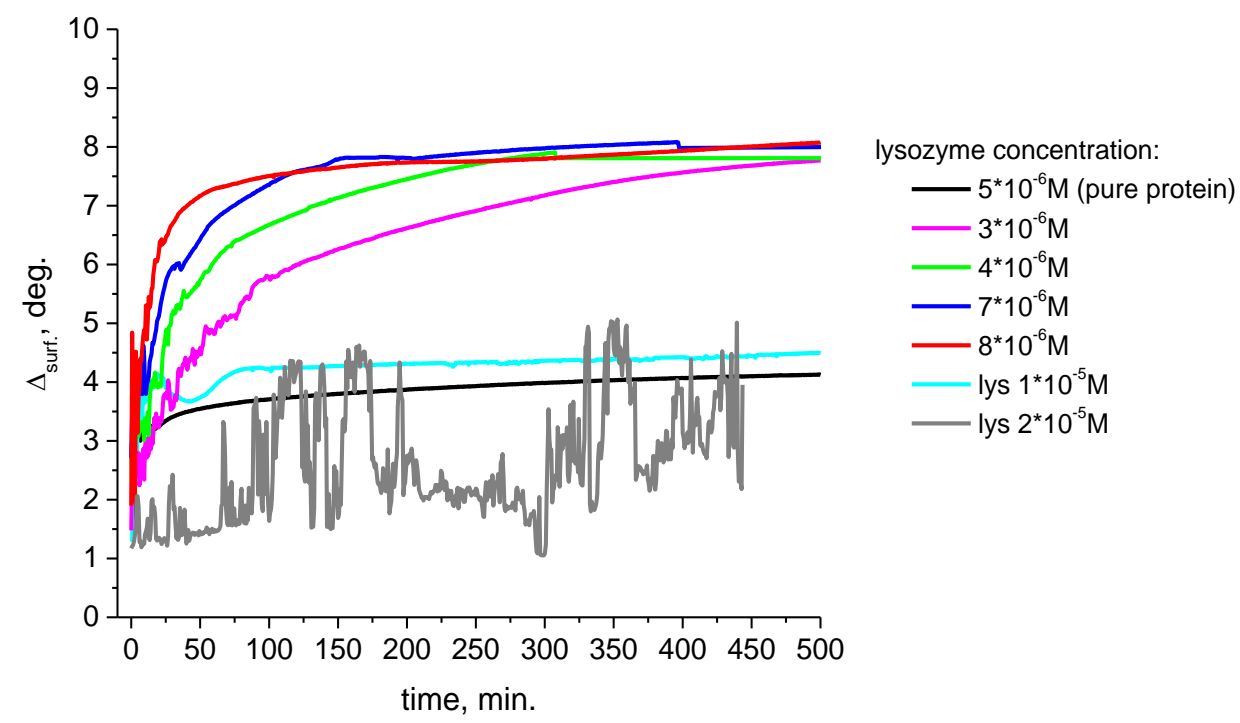

Fig. 5. Kinetic dependences of the ellipsometric angle $\Delta$ for mixed dispersions of silica nanoparticles $(0.2$ wt \%) and lysozyme at $\mathrm{pH} 7$ and at various protein concentrations.

At even higher concentrations than $1 \times 10^{-5} \mathrm{M}$, the ellipsometric measurements are hindered by the macroscopic inhomogeneity of the bulk solution.

The results of BAM confirm the conclusion that the adsorption of complexes occurs already at surface pressures close to those for solutions of pure lysozyme. One can observe the heterogeneity of the adsorption layer, which apparently leads to the fluctuations of the ellipsometric signal in Fig. 5, at the initial step of adsorption, a few minutes after the formation of a new surface for the sample at the lowest measured protein concentration (Fig. 6A). The adsorption layer becomes uniform with the increase of surface age, and images of the layer show only a continuous gray background (Fig. 6B, 6E, 6H). The formation of a continuous adsorption layer is easy to detect in a few hours after the beginning of adsorption in the concentration range from $1 \times 10^{-6} \mathrm{M}$ to $1 \times 10^{-5} \mathrm{M}$. A weak mechanical disturbance by a thin needle leads to the destruction of the continuous layer (Fig. 6C, 6F, 6I). The rate of formation of the continuous fragile adsorption layer depends on the protein concentration: the higher it is, the faster the layer is formed. For concentrations $<2 \times 10^{-6} \mathrm{M}$ a stable layer, which can be destroyed by a mechanical 
disturbance, is formed in about 10 hours or longer. At the same time, it takes less than one hour for concentrations higher than $5 \times 10^{-6} \mathrm{M}$ (Fig. 6I). At lysozyme concentrations less than $7 \times 10^{-6} \mathrm{M}$, the layer destruction resembles the destruction of a glass plate leading to the formation of splinters with straight edges and sharp apexes, i.e. the layer is extremely fragile. One can observe in Figs. 6C, 6F some bright regions corresponding to the layer of the lysozyme/nanoparticle complexes and dark regions of the free water surface. The formation of solid-like layers can occur already at surface pressures close to the values for pure lysozyme solutions. These findings indicate a significant surface concentration of nanoparticles already at intermediate steps of the adsorption, when the dynamic surface elasticity does not exceed the characteristic values for globular proteins. At higher concentrations $\left(>7 \times 10^{-6} \mathrm{M}\right)$, the layer becomes more ductile, and its destruction does not lead to sharp edges of the patches of the layer of lysozyme/nanoparticle complexes but the boundaries between the patches and the free water surface become smooth (Fig. 6I). Probably this behavior is a consequence of the increase of lysozyme concentration in the surface layer and the extension of the protein corona. 

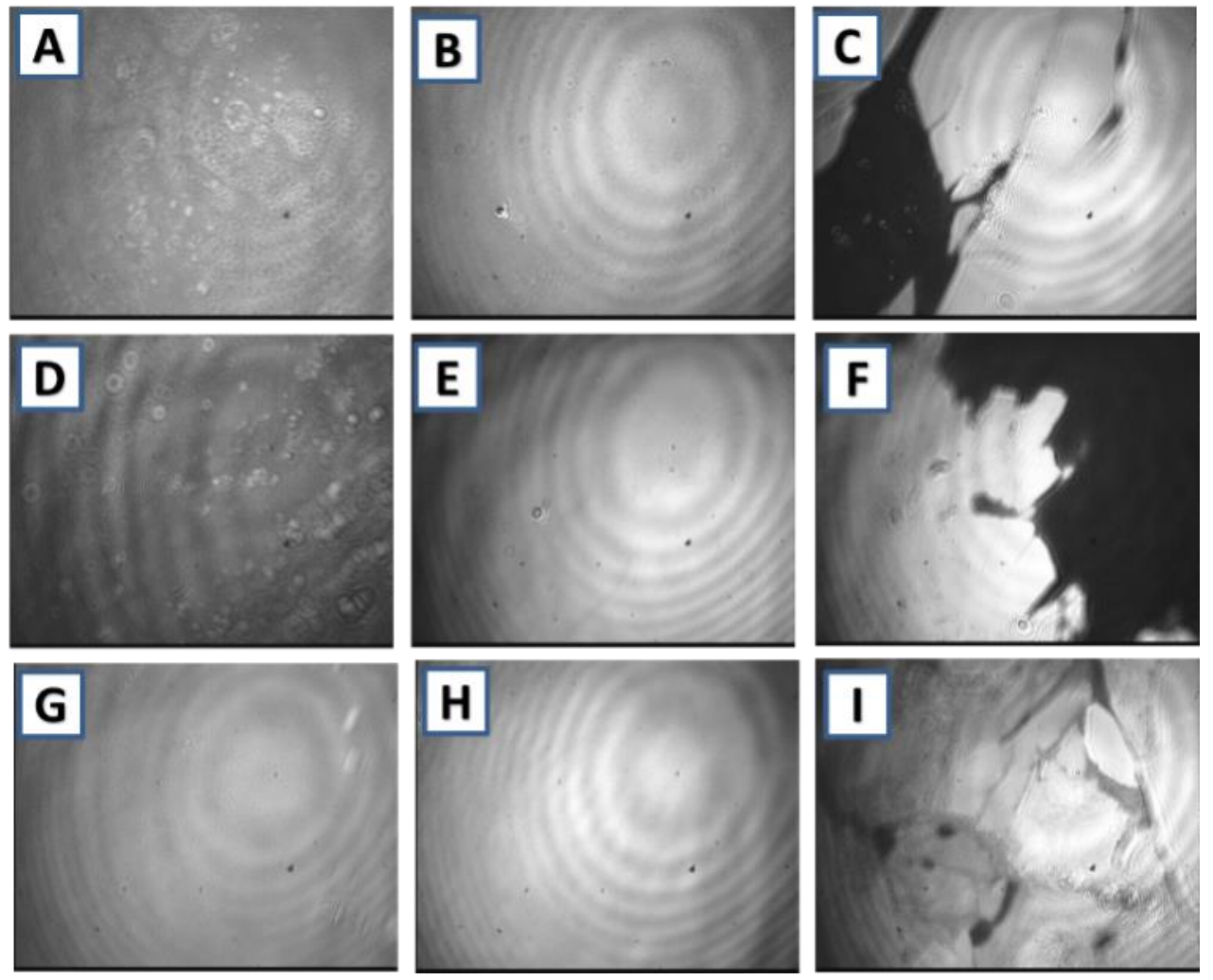

Fig. 6. BAM images of the adsorption layer in mixed dispersions of silica nanoparticles $(0.2$ wt. $\%)$ and lysozyme at $\mathrm{pH} 7$, at the protein concentrations $2 \times 10^{-6}(\mathrm{~A}, \mathrm{~B}, \mathrm{C}), 5 \times 10^{-6}(\mathrm{D}, \mathrm{E}, \mathrm{F}), 1 \times 10^{-5} \mathrm{M}(\mathrm{G}, \mathrm{H}, \mathrm{I})$ and surface ages of 2 minutes $(\mathrm{A}, \mathrm{D}, \mathrm{G}), 2$ hours $(\mathrm{E}, \mathrm{F}, \mathrm{H}, \mathrm{I})$ and 5 hours $(\mathrm{B}, \mathrm{C})$. Images $(\mathrm{C}, \mathrm{F}, \mathrm{I})$ were made after mechanical disturbance of the films. 

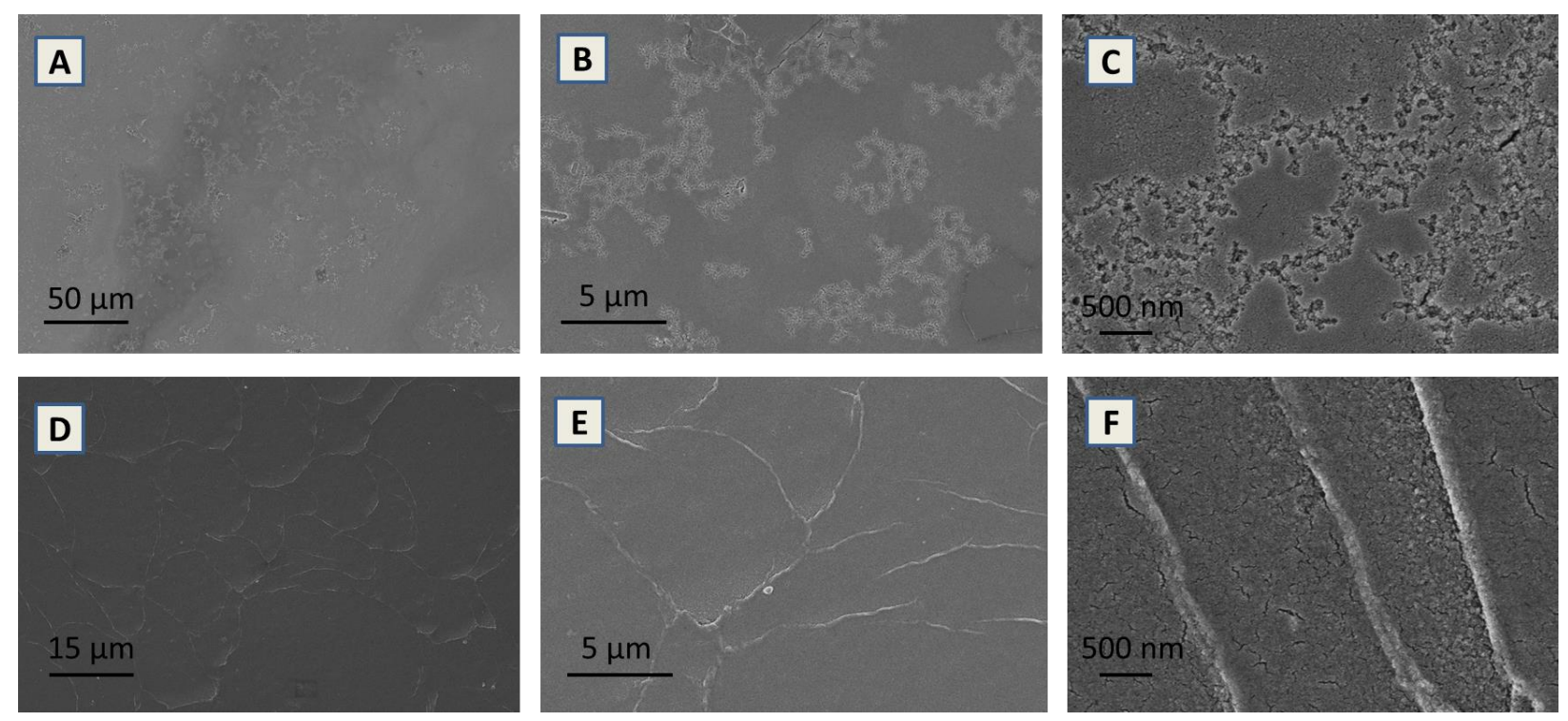

Fig. 7. SEM images at different magnifications (A - 1000, B - 10000, C - 50000, D - 3000, E - 10000, F - 40000) of the adsorption layer in mixed dispersions of silica nanoparticles (0.2 wt.\%) and lysozyme at pH 7 and protein concentrations of $2 \times 10^{-6}(\mathrm{~A}, \mathrm{~B}, \mathrm{C})$ and $5 \times 10^{-6} \mathrm{M}(\mathrm{D}, \mathrm{E}, \mathrm{F})$. The layer was transferred onto a solid substrate by the Langmuir-Schaefer method.

The images obtained by SEM demonstrate the changes of the microstructure of lysozyme/nanoparticle adsorption layers with increasing protein concentration (Fig. 7). At low concentrations $\left(5 \times 10^{-7}\right.$ and $1 \times$ $10^{-6} \mathrm{M}$ ), the obtained images are characterized by an only slight roughness (supporting information, Fig. 5S). As the protein concentration increases up to $2 \times 10^{-6} \mathrm{M}$ (Fig. 7A, 7B, 7C), one can observe individual branched and therefore filamentous aggregates. It is possible to assume that these aggregates consist of nanoparticles interconnected due to the attraction of protein shells. At a higher concentration of lysozyme $\left(5 \times 10^{-6} \mathrm{M}\right.$, Fig. 7D, 7F, 7G), one can observe that the adsorption layer consists of separate domains. The thickness of the layer increases at the boundaries between the domains. This effect can be connected with a partial superposition of the neighboring domains in the course of the layer transfer from the liquid surface onto the solid substrate. At high magnification, it is possible to see that the domains are also inhomogeneous and contain microscopic cracks (Fig. 7F). 
The application of AFM allows observation of the images of the adsorption layer at higher resolution. Figs. 8 and 9 show the images of the mixed layers of silica nanoparticles with lysozyme transferred onto a mica surfaces by the Langmuir-Blodgett method at protein concentrations of $2 \times 10^{-6}$ and $5 \times 10^{-6} \mathrm{M}$, respectively. The numerous closely packed objects on the images have the size close to that of nanoparticles and are evidently the protein/nanoparticle complexes. Even low bulk concentrations of the protein lead to the formation of amphiphilic protein/nanoparticle complexes and their strong adsorption at the air/water interface (Fig. 8A, 8B). The packing of the complexes at the interface becomes denser at lysozyme concentration of $5 \times 10^{-6} \mathrm{M}$ (Fig. 9B). The additional information on the size of complexes and the approximate distance between them is given by the cross-section images in supporting information (Figs. 6S and 7S). The protein coronas reduce the electrostatic repulsion between the nanoparticles and, at the same time, increase the attraction between the complexes, probably due to the interaction of oppositely charged groups at the surface of the particles covered by the protein, thereby leading to their denser packing. 

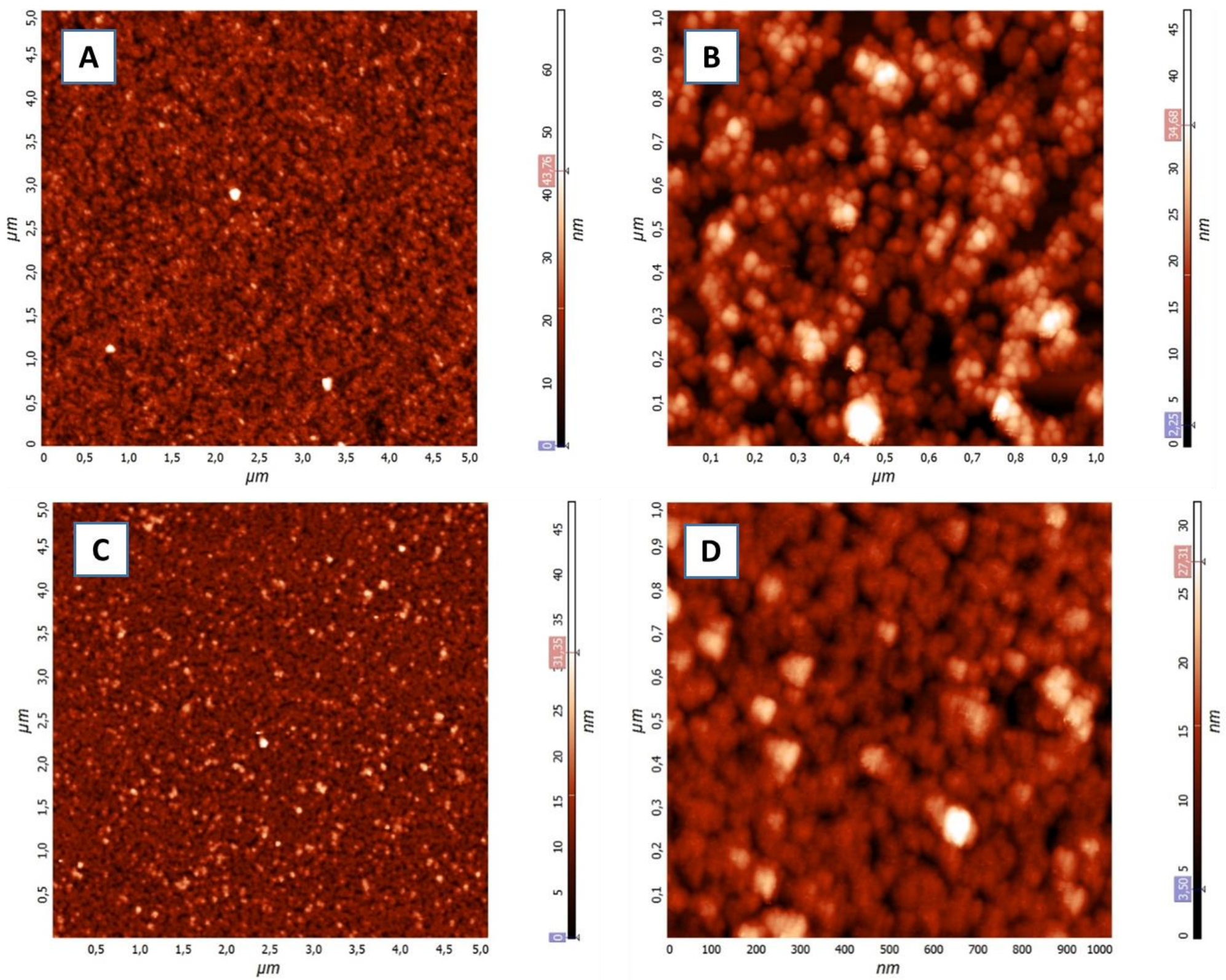

Fig. 8. AFM images of the adsorption layer in mixed dispersions of silica nanoparticles $(0.2 \mathrm{wt} . \%)$ and lysozyme at $\mathrm{pH} 7$, and at a protein concentration of $2 \times 10^{-6} \mathrm{M}(\mathrm{A}, \mathrm{B})$ and $5 \times 10^{-6} \mathrm{M}(\mathrm{C}, \mathrm{D})$. The layer was transferred onto a solid substrate by the Langmuir-Blodgett method. 
a)
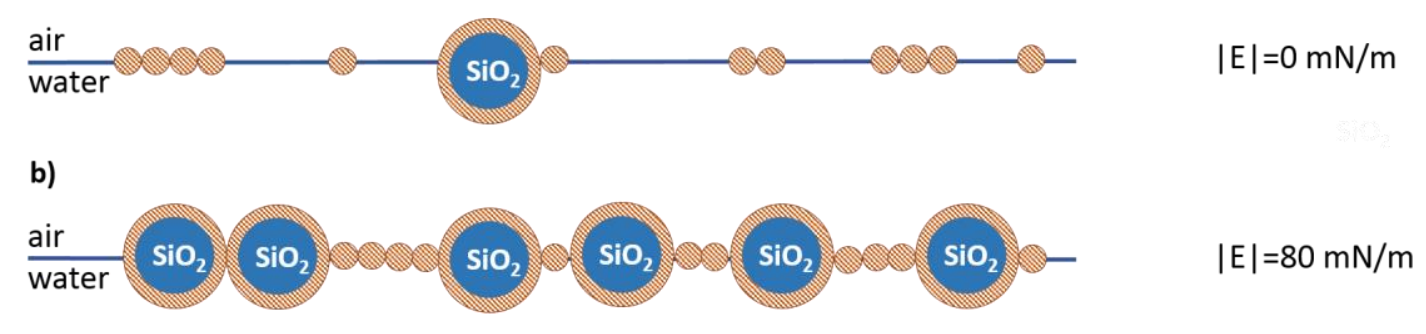

c)

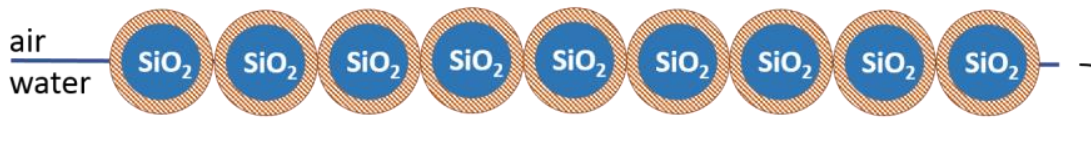

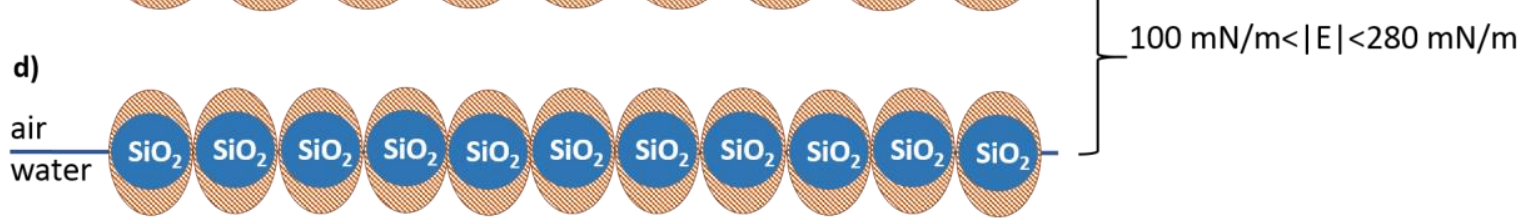

Fig. 9. Scheme of the surface layer structure of mixed dispersions of silica nanoparticles and lysozyme at different steps of adsorption.

\section{Discussion}

The adsorption rate of lysozyme molecule is faster than of the protein/nanoparticle complexes because of the higher diffusion coefficient of the protein molecules. Therefore it is possible to assume that the adsorption layer consists mainly of lysozyme globules at the beginning of adsorption (Fig. 9a). The first adsorbed lysozyme molecules form separate islands of a condensed surface phase and the surface elasticity is close to zero up to the moment when the islands start to interact and form a continuous adsorption layer ${ }^{48,49}$. The dynamic surface properties start to increase after that. The surface concentration of the protein/nanoparticle complexes increases gradually at this step but the surface properties are still determined by the interactions between protein molecules and probably between the nanoparticle coronas and the macromolecules not bound by the nanoparticles or between the coronas of proteins with uncharged tertiary structure (Fig. 9b). In this case, the dynamic surface properties are typical for solutions of globular proteins and change only slightly with the increase of the protein bulk concentration (Figs. 2, 
3). At the same time, the surface activity of lysozyme/nanoparticle complexes exceeds the activity of protein molecules, their surface concentration increases further and they can displace some protein molecules from the interface. The effect of the complexes on the dynamic surface properties becomes noticeable only when their surface concentration exceeds a certain critical value and they start to form a continuous network at the interface (Fig. 9c). The dynamic surface elasticity and dynamic surface pressure grow up fast again and reach values. In particular, the dynamic surface elasticity can be more than 2 times higher than the corresponding value for pure lysozyme solutions (Fig. 3). The observed effect is obviously a consequence of the influence of the solid cores of the complexes on the dynamic surface properties. The high surface pressure indicates that the concentration of hydrophobic amino acid residues in the proximal region of the surface layer of lysozyme/nanoparticle dispersions is higher than in this region for lysozyme solutions. It is possible that the surface properties of separate lysozyme molecules remain in the adsorption layer even at high surface pressures and contribute to the response of the complete layer to the surface dilation. The high surface concentration and the compression of the adsorption layer can result in noticeable deformations of the protein coronas (Fig. 9d).

Note that the observed kinetic dependencies of the dynamic surface properties with transitions from fast to slow and again to fast changes (Figs. 2, 3) are similar to the results for mixed solutions of DNA and a cationic surfactant ${ }^{50}$. In the latter case, the corresponding changes of the surface properties were connected with a transition between two surface phases: a surfactant adsorption layer and a layer formed by a network of DNA/surfactant complexes. At the same time, the kinetic dependencies of the given study are smoother and probably do not indicate a phase transition of the first order but a continuous change between two states of the adsorption layer with different properties.

\section{Conclusions}

Interactions of lysozyme with silica nanoparticles in aqueous solution lead to the formation of stable complexes at concentrations not exceeding $5 \times 10^{-6} \mathrm{M}$. The stoichiometry of such complexes approaches 
saturation with about 150 protein molecules per nanoparticle of 20 -nm average diameter at a lysozyme concentration of $5 \times 10^{-6} \mathrm{M}$ under the conditions studied ${ }^{20}$. Various aspects of the surface activity of these protein/nanoparticle complexes have formed the subject of the present work.

The obtained results allow distinction of two main steps of adsorption. In a first step, the adsorption of lysozyme/nanoparticle complexes does not lead to noticeable distinctions from the surface properties of lysozyme solutions. The dynamic surface elasticity and dynamic surface pressure increase, reaching values characteristic for solutions of globular proteins, and they change only slightly after that (dilatational surface rheology). These slight changes of the surface properties can be attributed to the further adsorption of protein/nanoparticle complexes and the gradual displacement of the previously adsorbed protein molecules from the interface. The adsorption layer appeared inhomogeneous and mobile for the first 20-70 minutes after surface formation (ellipsometry), while two-dimensional aggregates of the adsorbed complexes have been shown to form a fragile solid-like layer within a few hours after the creation of a new surface (Brewster angle microscopy). This layer could be destroyed by external mechanical perturbations. In the second step, the adsorption of the complexes continues, and the adsorption layer becomes denser. This leads again to a fast increase of the dynamic surface elasticity and dynamic surface pressure, reaching $\sim 280 \mathrm{mN} / \mathrm{m}$ and $27 \mathrm{mN} / \mathrm{m}$, respectively. The dynamic surface elasticity proves to be a linear function of the surface pressure in the entire range of investigated protein concentrations. It indicates the similarity of the globule-globule, globule-corona of nanoparticles and corona-corona interactions. Therefore it can be concluded that the lysozyme globular structure is preserved in the shell of nanoparticles in the course of their adsorption and the subsequent compression of the adsorption layer. Two different imaging techniques applied to films of the protein/nanoparticle complexes transferred to solid substrates confirmed the high surface concentration of the complexes in the adsorption layer (atomic force microscopy and scanning electron microscopy).

The application of five surface-sensitive techniques in this work has provided new insight into the surface properties of a model system composed of a very well-studied protein and a hydrophilic nanoparticle. 
Adsorption dynamics at the air/water interface from competition between protein/nanoparticle complexes and free protein, and the resulting interfacial morphologies, have been resolved in parallel for the first time, and offer the possibility to adopt similar approaches of related systems.

\section{Acknowledgements}

This work was supported by the Russian Foundation of Basic Research, and the Ministry of Science and Technology of Taiwan (joint project no. 16-53-52034). O.Y.M. is also grateful to the Russian Foundation of Basic Research for the project for young researchers (project no. 18-33-00015).

\section{Supporting Information}

Figures showing surface tension oscillations for mixed lysozyme/ $\mathrm{SiO}_{2}$ dispersions, kinetic dependencies of surface tension for mixed solutions, kinetic dependencies of the dynamic surface elasticity and surface tension of lysozyme solutions, dependencies of the dynamic surface elasticity on surface pressure for lysozyme solutions, SEM image of the adsorption layer in mixed lysozyme/SiO ${ }_{2}$ dispersion, cross sections of the adsorption layer obtained by AFM.

\section{References}

(1) Corbo, C.; Molinaro, R.; Tabatabaei, M.; Farokhzad, O. C.; Mahmoudi, M. Personalized Protein Corona on Nanoparticles and Its Clinical Implications. Biomater. Sci. 2017, 5 (3), 378-387. https://doi.org/10.1039/C6BM00921B.

(2) Zheng, K.; Lu, M.; Liu, Y.; Chen, Q.; Taccardi, N.; Norbert, H.; Boccaccini, A. R. Monodispersed Lysozyme-Functionalized Bioactive Glass Nanoparticles with Antibacterial and Anticancer Activities. Biomed. Mater. 2016, 11, 35012-35025. https://doi.org/10.1088/1748$605 X / 11 / 3 / 035012$.

(3) Li, J.; Mao, H.; Kawazoe, N.; Chen, G. Insight into the Interactions between Nanoparticles and 
Cells. Biomater. Sci. 2017, 5 (2), 173-189. https://doi.org/10.1039/C6BM00714G.

(4) Caracciolo, G.; Farokhzad, O. C.; Mahmoudi, M. Biological Identity of Nanoparticles In Vivo: Clinical Implications of the Protein Corona. Trends Biotechnol. 2017, 35 (3), 257-264. https://doi.org/10.1016/j.tibtech.2016.08.011.

(5) Neagu, M.; Piperigkou, Z.; Karamanou, K.; Engin, A. B.; Docea, A. O.; Constantin, C.; Negrei, C.; Nikitovic, D.; Tsatsakis, A. Protein Bio-Corona: Critical Issue in Immune Nanotoxicology. Arch. Toxicol. 2017, 91 (3), 1031-1048. https://doi.org/10.1007/s00204-016-1797-5.

(6) Mahmoudi, M.; Lynch, I.; Ejtehadi, M. R.; Monopoli, M. P.; Bombelli, F. B.; Laurent, S. ProteinNanoparticle Interactions: Opportunities and Challenges. Chem. Rev. 2011, 111 (9), 5610-5637. https://doi.org/10.1021/cr100440g.

(7) Casals, E.; Puntes, V. F. Inorganic Nanoparticle Biomolecular Corona: Formation, Evolution and Biological Impact. Nanomedicine (Lond). 2012, 7 (12), 1917-1930. https://doi.org/10.2217/nnm.12.169.

(8) Monopoli, M. P.; Walczyk, D.; Campbell, A.; Elia, G.; Lynch, I.; Baldelli Bombelli, F.; Dawson, K. a. Physical-Chemical Aspects of Protein Corona: Relevance to in Vitro and in Vivo Biological Impacts of Nanoparticles. J. Am. Chem. Soc. 2011, 133 (8), 2525-2534. https://doi.org/10.1021/ja107583h.

(9) Shang, L.; Yang, L.; Seiter, J.; Heinle, M.; Brenner-Weiss, G.; Gerthsen, D.; Nienhaus, G. U. Nanoparticles Interacting with Proteins and Cells: A Systematic Study of Protein Surface Charge Effects. Adv. Mater. Interfaces 2014, 1 (2), n/a-n/a. https://doi.org/10.1002/admi.201300079.

(10) Lynch, I.; Dawson, K. a. Protein-Nanoparticle Interactions. Nano Today 2008, 3 (1-2), 40-47. https://doi.org/10.1016/S1748-0132(08)70014-8.

(11) Mahmoudi, M.; Kalhor, H. R.; Laurent, S.; Lynch, I. Protein Fibrillation and Nanoparticle Interactions: Opportunities and Challenges. Nanoscale 2013, 5 (7), 2570-2588. https://doi.org/10.1039/c3nr33193h. 
(12) Meissner, J.; Prause, A.; Bharti, B.; Findenegg, G. H. Characterization of Protein Adsorption onto Silica Nanoparticles: Influence of PH and Ionic Strength. Colloid Polym. Sci. 2015, 293 (11), 3381-3391. https://doi.org/10.1007/s00396-015-3754-x.

(13) Shrivastava, S.; Nuffer, J. H.; Siegel, R. W.; Dordick, J. S. Position-Specific Chemical Modification and Quantitative Proteomics Disclose Protein Orientation Adsorbed on Silica Nanoparticles. Nano Lett. 2012, 12 (3), 1583-1587. https://doi.org/10.1021/nl2044524.

(14) Satzer, P.; Svec, F.; Sekot, G.; Jungbauer, A. Protein Adsorption onto Nanoparticles Induces Conformational Changes: Particle Size Dependency, Kinetics, and Mechanisms. Eng. Life Sci. 2016, 16 (3), 238-246. https://doi.org/10.1002/elsc.201500059.

(15) Cedervall, T.; Lynch, I.; Lindman, S.; Berggård, T.; Thulin, E.; Nilsson, H.; Dawson, K. a; Linse, S. Understanding the Nanoparticle-Protein Corona Using Methods to Quantify Exchange Rates and Affinities of Proteins for Nanoparticles. Proc. Natl. Acad. Sci. U. S. A. 2007, 104 (7), 2050-2055. https://doi.org/10.1073/pnas.0608582104.

(16) Larsericsdotter, H.; Oscarsson, S.; Buijs, J. Thermodynamic Analysis of Proteins Adsorbed on Silica Particles: Electrostatic Effects. J. Colloid Interface Sci. 2001, 237 (1), 98-103. https://doi.org/10.1006/jcis.2001.7485.

(17) Wu, X.; Narsimhan, G. Effect of Surface Concentration on Secondary and Tertiary Conformational Changes of Lysozyme Adsorbed on Silica Nanoparticles. Biochim. Biophys. Acta - Proteins Proteomics 2008, 1784 (11), 1694-1701. https://doi.org/10.1016/j.bbapap.2008.06.008.

(18) Felsovalyi, F.; Mangiagalli, P.; Bureau, C.; Kumar, S. K.; Banta, S. Reversibility of the Adsorption of Lysozyme on Silica. Langmuir 2011, 27 (19), 11873-11882. https://doi.org/10.1021/la202585r.

(19) Vertegel, A. A.; Siegel, R. W.; Dordick, J. S. Silica Nanoparticle Size Influences the Structure and Enzymatic Activity of Adsorbed Lysozyme. Langmuir 2004, 20 (16), 6800-6807. https://doi.org/10.1021/la0497200.

(20) Kumar, S.; Aswal, V. K.; Kohlbrecher, J. SANS and UV-Vis Spectroscopy Studies of Resultant 
Structure from Lysozyme Adsorption on Silica Nanoparticles. Langmuir 2011, 27 (16), 1016710173. https://doi.org/10.1021/la201291k.

(21) Kubiak-Ossowska, K.; Mulheran, P. A. Mechanism of Hen Egg White Lysozyme Adsorption on a Charged Solid Surface. Langmuir 2010, 26 (20), 15954-15965. https://doi.org/10.1021/la102960m.

(22) Yu, G.; Zhou, J. Understanding the Curvature Effect of Silica Nanoparticles on Lysozyme Adsorption Orientation and Conformation: A Mesoscopic Coarse-Grained Simulation Study. Phys. Chem. Chem. Phys. 2016, 18 (34), 23500-23507. https://doi.org/10.1039/C6CP01478J.

(23) Daly, S. M.; Przybycien, T. M.; Tilton, R. D. Coverage-Dependent Orientation of Lysozyme Adsorbed on Silica. Langmuir 2003, 19 (9), 3848-3857. https://doi.org/10.1021/la026690x.

(24) Weichsel, U.; Segets, D.; Janeke, S.; Peukert, W. Enhanced Nucleation of Lysozyme Using Inorganic Silica Seed Particles of Different Sizes. Cryst. Growth Des. 2015, 15 (8), 3582-3593. https://doi.org/10.1021/cg501681g.

(25) Kumar, S.; Yadav, I.; Aswal, V. K.; Kohlbrecher, J. Structure and Interaction of NanoparticleProtein Complexes. Langmuir 2018, 34 (20), 5679-5695. https://doi.org/10.1021/acs.langmuir.8b00110.

(26) Yadav, I.; Aswal, V. K.; Kohlbrecher, J. Size-Dependent Interaction of Silica Nanoparticles with Lysozyme and Bovine Serum Albumin Proteins. Phys. Rev. E - Stat. Nonlinear, Soft Matter Phys. 2016, 93 (5), 1-11. https://doi.org/10.1103/PhysRevE.93.052601.

(27) Kundu, S.; Das, K.; Mehan, S.; Aswal, V. K.; Kohlbrecher, J. Structure and Interaction among Protein and Nanoparticle Mixture in Solution: Effect of Temperature. Chem. Phys. Lett. 2015, 641, 68-73. https://doi.org/10.1016/j.cplett.2015.10.039.

(28) Vitali, M.; Rigamonti, V.; Natalello, A.; Colzani, B.; Avvakumova, S.; Brocca, S.; Santambrogio, C.; Narkiewicz, J.; Legname, G.; Colombo, M.; et al. Conformational Properties of Intrinsically Disordered Proteins Bound to the Surface of Silica Nanoparticles. Biochim. Biophys. Acta - Gen. 
Subj. 2018, 1862 (7), 1556-1564. https://doi.org/10.1016/j.bbagen.2018.03.026.

(29) Ang, J. C.; Henderson, M. J.; Campbell, R. A.; Lin, J.-M.; Yaron, P. N.; Nelson, A.; Faunce, T.; White, J. W. Human Serum Albumin Binding to Silica Nanoparticles - Effect of Protein Fatty Acid Ligand. Phys. Chem. Chem. Phys. 2014, 16 (21), 10157-10168.

https://doi.org/10.1039/c4cp00293h.

(30) Ang, J. C.; Lin, J.-M.; Yaron, P. N.; White, J. W. Protein Trapping of Silicananoparticles. Soft Matter 2010, 6 (2), 383-390. https://doi.org/10.1039/B919256E.

(31) Tihonov, M. M. M.; Milyaeva, O. Y. Y.; Noskov, B. A. A. Dynamic Surface Properties of Lysozyme Solutions. Impact of Urea and Guanidine Hydrochloride. Colloids Surfaces B Biointerfaces 2015, 129, 114-120. https://doi.org/10.1016/j.colsurfb.2015.03.034.

(32) Bykov, A. G.; Gochev, G.; Loglio, G.; Miller, R.; Panda, A. K.; Noskov, B. A. Dynamic Surface Properties of Mixed Monolayers of Polystyrene Micro- and Nanoparticles with DPPC. Colloids Surfaces A Physicochem. Eng. Asp. 2017, 521, 239-246. https://doi.org/10.1016/j.colsurfa.2016.11.006.

(33) Noskov, B. A.; Mikhailovskaya, A. A.; Lin, S.-Y.; Loglio, G.; Miller, R. Bovine Serum Albumin Unfolding at the Air/Water Interface as Studied by Dilational Surface Rheology. Langmuir 2010, 26 (22), 17225-17231. https://doi.org/10.1021/la103360h.

(34) Noskov, B. A. Protein Conformational Transitions at the Liquid-Gas Interface as Studied by Dilational Surface Rheology. Adv. Colloid Interface Sci. 2014, 206, 222-238. https://doi.org/10.1016/j.cis.2013.10.024.

(35) Kokelaar, J. J.; Prins, A.; De Gee, M. A New Method for Measuring the Surface Dilational Modulus of a Liquid. J. Colloid Interface Sci. 1991, 146 (2), 507-511. https://doi.org/10.1016/0021-9797(91)90214-S.

(36) Bykov, A. G.; Lin, S.-Y.; Loglio, G.; Miller, R.; Noskov, B. a. Kinetics of Adsorption Layer Formation in Solutions of Polyacid/Surfactant Complexes. J. Phys. Chem. C 2009, 113 (14), 5664- 
5671. https://doi.org/10.1021/jp810471y.

(37) Motschmann, H.; Teppner, R. Novel Methods to Study Interfacial Layers.; Elsevier, 2001; Vol. 45. https://doi.org/10.1080/10826068.2014.940969.

(38) Moren, A. K.; Khan, A. Phase Equilibria of an Anionic Surfactant (Sodium Dodecyl Sulfate) and an Oppositely Charged Protein (Lysozyme) in Water. Langmuir 1995, 11 (10), 3636-3643. https://doi.org/10.1021/la00010a009.

(39) Yadav, I.; Aswal, V. K.; Kohlbrecher, J. Electrolyte Effect on the Phase Behavior of Silica Nanoparticles with Lysozyme and Bovine-Serum-Albumin Proteins. Phys. Rev. E - Stat. Nonlinear, Soft Matter Phys. 2015, 91 (5), 1-9. https://doi.org/10.1103/PhysRevE.91.052306.

(40) Bharti, B.; Meissner, J.; Klapp, S. H. L.; Findenegg, G. H. Bridging Interactions of Proteins with Silica Nanoparticles: The Influence of PH, Ionic Strength and Protein Concentration. Soft Matter 2014, 10 (5), 718-728. https://doi.org/10.1039/C3SM52401A.

(41) Yadav, I.; Kumar, S.; Aswal, V. K.; Kohlbrecher, J. Small-Angle Neutron Scattering Study of Differences in Phase Behavior of Silica Nanoparticles in the Presence of Lysozyme and Bovine Serum Albumin Proteins. Phys. Rev. E 2014, 89 (3), 032304. https://doi.org/10.1103/PhysRevE.89.032304.

(42) Bharti, B.; Meissner, J.; Findenegg, G. H. Aggregation of Silica Nanoparticles Directed by Adsorption of Lysozyme. Langmuir 2011, 27 (16), 9823-9833. https://doi.org/10.1021/la201898v.

(43) Yazhgur, P. A.; Noskov, B. A.; Liggieri, L.; Lin, S.-Y. Y.; Loglio, G.; Miller, R.; Ravera, F. Dynamic Properties of Mixed Nanoparticle/Surfactant Adsorption Layers. Soft Matter 2013, 9 (12), 3305-3314. https://doi.org/10.1039/c3sm27304k.

(44) Ulaganathan, V.; Retzlaff, I.; Won, J. Y.; Gochev, G.; Gehin-Delval, C.; Leser, M.; Noskov, B. A.; Miller, R. Beta-Lactoglobulin Adsorption Layers at the Water/Air Surface: 1. Adsorption Kinetics and Surface Pressure Isotherm: Effect of PH and Ionic Strength. Colloids Surfaces A Physicochem. Eng. Asp. 2017, 519, 153-160. https://doi.org/10.1016/j.colsurfa.2016.03.008. 
(45) Khlebtsov, B. N.; Khanadeev, V. A.; Khlebtsov, N. G.; V. Determination of the Size, Concentration , and Refractive Index of Silica Nanoparticles from Turbidity Spectra. Langmuir 2008, 24 (16), 8964-8970.

(46) Malmstein, M. Ellipsometry Studies of Protein Layers Adsorbed at Hydrophobic Surfaces. J. Colloid Interface Sci. 1994, 166, 333-342.

(47) Campbell, R. A.; Ang, J. C.; Sebastiani, F.; Tummino, A.; White, J. W. Spread Films of Human Serum Albumin at the Air-Water Interface: Optimization, Morphology, and Durability. Langmuir 2015, 31 (50), 13535-13542. https://doi.org/10.1021/acs.langmuir.5b03349.

(48) Erickson, J. S.; Sundaram, S.; Stebe, K. J. Evidence That the Induction Time in the Surface Pressure Evolution of Lysozyme Solutions Is Caused by a Surface Phase Transition. Langmuir 2000, 16 (11), 5072-5078. https://doi.org/10.1021/la991179y.

(49) Campbell, R. A.; Tummino, A.; Varga, I.; Milyaeva, O. Y.; Krycki, M. M.; Lin, S. Y.; Laux, V.; Haertlein, M.; Forsyth, V. T.; Noskov, B. A. Adsorption of Denaturated Lysozyme at the AirWater Interface: Structure and Morphology. Langmuir 2018, 34 (17), 5020-5029. https://doi.org/10.1021/acs.langmuir.8b00545.

(50) Lyadinskaya, V. V.; Lin, S. Y.; Michailov, A. V.; Povolotskiy, A. V.; Noskov, B. A. Phase Transitions in DNA/Surfactant Adsorption Layers. Langmuir 2016, 32 (50), 13435-13445. https://doi.org/10.1021/acs.langmuir.6b03396. 
Table of Contents Image

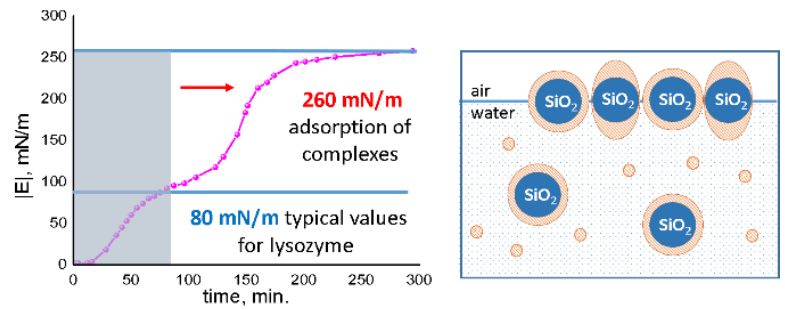

Silica nanoparticles adsorbs on air/water interface due to protein corona and strongly affects dynamic surface elasticity and dynamic surface tension. 